\title{
Myocardial infarction and thrombophilia: easy to miss the correct diagnosis
}

\author{
Jasna Čerkez \\ Habek $^{1,2 *}$, \\ Jozica Šikić ${ }^{13}$, \\ Petra Grubić', \\ Dean Strinić', \\ Dario Gulin ${ }^{1,3}$
}

'University Hospital "Sveti Duh", Zagreb, Croatia

${ }^{2}$ Croatian Catholic University, Zagreb, Croatia

${ }^{3}$ University of Zagreb School of Medicine, Zagreb, Croatia

RECEIVED:

January 30, 2018

ACCEPTED:

February 10, 2018

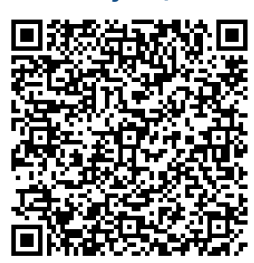

$\square$ Cardiologia Croatica 2018:13(1-2):26.
KEYWORDS: myocardial infarction, thrombophilia, thrombus.

CITATION: Cardiol Croat. 2018;13(1-2):26. | https://doi.org/10.15836/ccar2018.26

*ADDRESS FOR CORRESPONDENCE: Jasna Čerkez Habek, Klinička bolnica „Sveti Duh“, Sv. Duh 64, HR-10000 Zagreb, Croatia. / Phone: +385-91-3712-966 / E-mail: jasna.habek@gmail.com

ORCID: Jasna Čerkez Habek, https://orcid.org/0000-0003-3177-3797 • Jozica Šikić, https://orcid.org/0000-0003-4488-0559 Petra Grubić, https://orcid.org/0000-0002-2587-1932 • Dean Strinić, https://orcid.org/0000-0001-6345-2037

Dario Gulin, https://orcid.org/0000-0001-8502-7816

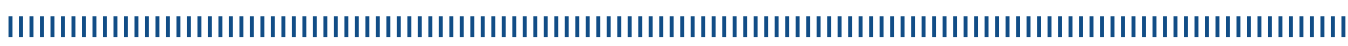

Background: Myocardial infarction with ST elevation has incidence rate ranged from 43 to 144 per 100 000 per year ${ }^{1}$. Differentiation of arterial thrombosis from most common causes of myocardial infarction, rupture or erosion of atherosclerotic plaque, especially in younger patients without or less cardiovascular risk factors and atherosclerosis, can be challenging.

Case report: 47-years-old lady was admitted to our clinic 1 hour after onset of a chest pain. Risk factors for cardiovascular disease were positive family history, dyslipidemia and nicotinism. ECG revealed ST elevation from V1-V4 to $3 \mathrm{~mm}$. Just after ECG was performed, the patient was defibrillated with 120J because of ventricular fibrillation. An emergency coronary angiography pointed out a thrombotic occlusion of the proximal left anterior descending coronary artery, treated with implantation of the drug-eluting stent $(3.0 \times 18 \mathrm{~mm})$. Before discharge echocardiography showed non-dilated left ventricle with mild reduction in systolic function (EF 45-50\%). Hypokinesis of apical segment of anterior wall and apex was noted with unexpected two prominent sessile thrombi. Initial therapy with ticagrelor and aspirin was changed in clopidogrel, aspirin, nadroparin initially until the therapeutic range was achieved with warfarin. During the triplet therapy due to a menorrhagia severe anemia occurs, treated with intrauterine levonorgestrel release device. Thrombophilia test showed that lady is homozygous for MTHFR and heterozygous for the PAIl mutation

Discussion: Inherited thrombophilia is a genetic disorder predisposing thrombosis which may occasionally manifest, usually in the presence of trigger factors ${ }^{2}$. It induces a hypercoagulable state, which, together with other cardiovascular risk factors, may explain the arterial thrombosis in this younger patient and thrombus formation in the ventricle, although time to balloon time was less than two hours and without aneurysmal formation of the left ventricle. It seems like thrombophilia may favor myocardial infarction, but is not able to cause it per se ${ }^{3}$.

Conclusion: Inherited thrombophilia is responsible for a small percentage of acute myocardial infarctions, and should be suspected mostly in younger patients. An absence of diagnosis leads to inadequate therapy and poor prognosis.

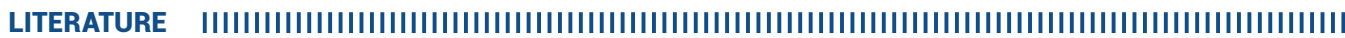

1. Widimsky P, Wijns W, Fajadet J, de Belder M, Knot J, Aaberge L, et al; European Association for Percutaneous Cardiovascular Interventions. Reperfusion therapy for ST elevation acute myocardial infarction in Europe: description of the current situation in 30 countries. Eur Heart J. 2010 Apr;31(8):943-57. https://doi.org/10.1093/eurheartj/ehp492

2. Pascalau L, Valcovici M, Turi V, Dragan S. Thrombophilia as a cardiovascular risk factor for acute myocardial infarction at young age $\ominus$ case report. Romanian Journal of Cardiology. 2015;25(2):179-184. Available at:

https://www.romanianjournalcardiology.ro/wp-content/uploads/2015/10/Thrombophilia-as-a-cardiovascular-risk-factor-for-acute.pdf

3. Ferrante G, Nakano M, Prati F, Niccoli G, Mallus MT, Ramazzotti V, et al. High levels of systemic myeloperoxidase are associated with coronary plaque erosion in patients with acute coronary syndromes: a clinicopathological study. Circulation. 2010 Dec 14;122(24):2505-13. https://doi.org/10.1161/CIRCULATIONAHA.110.955302 